\title{
EDUCAÇÃO, SABER E EMANCIPAÇÃO HUMANA: UMA EPISTEMOLOGIZAÇÃO POSSÍVEL
}

\section{EDUCATION, KNOW AND HUMAN EMANCIPATION: A POSSIBLE EPISTEMOLOGIZATION}

\begin{abstract}
José Carlos Gomes de Campos
Graduado em História pela Universidade Norte do Paraná, Graduando em Ciências Sociais pela Universidade Estadual de Santa Cruz (UESC), Especializando em Educação Científica e Cidadania pelo IFBaiano - Campus Uruçuca, Professor da rede estadual de Minas Gerais. jose.cgc@educacao.mg.gov.br

Adeilton Dias Alves

Doutor em Ciências Sociais pela Universidade Federal do Rio Grande do Norte (UFRN), Professor efetivo do IFBaiano - Campus Uruçuca. adeilton dias@hotmail.com
\end{abstract}

\section{Resumo}

A educação sempre foi tida como uma área promissora para qualquer nação. Ferramenta na promoção da emancipação humana e na quebra das inúmeras desigualdades sociais. O presente trabalho traz algumas reflexões epistemológicas a cerca da constituição dos sistemas educacionais, em especial no Brasil, e como esses sistemas corroboram com uma política eurocêntrica do saber, e, como esse saber produzem "verdades" através dos inúmeros discursos hegemônicos proferidos pelos os que detêm o saber-poder. Por fim, aponta-se a necessidade do exercício para uma (des) construção desses sistemas, a fim, de tornar a educação um verdadeiro direito humano, alicerçado na pluralidade e na diversidade cultural dos saberes.

Palavras-chave: Direito Humano; Educação; Emancipação; Saber-Poder.

\begin{abstract}
Education has always been a promising area for any nation. Tool to promote human emancipation and break the various social inequalities. The present work brings some epistemological reflections and about the constitution of educational systems, especially in Brazil, and how these systems corroborate with a European saber policy, and, how this saber produces "truths" through numbers of hegemonic speeches given by that holds the know-power. Finally, the need to exercise a (de) construction of these systems is indicated, an end, to become a true human right, based on the plurality and cultural diversity of the sabers.
\end{abstract}

Keywords: Human Right; Education; Emancipation; Know-Power. 


\section{Introdução}

Os sistemas educacionais em todo o mundo seguem determinados padrões, modelos e técnicas, que, por muitas vezes são copiadas e disseminadas em diversas culturas. A exemplo disso é o modelo de educação que foi imposta pelo modelo europeu à América. Baseado num pensamento filosófico eurocêntrico, ou seja, onde a Europa é o centro de todas as coisas, dentre elas, o saber. Onde, "foi estabelecida uma relação de dominação direta, política, social e cultural dos europeus sobre os conquistados de todos os continentes. Essa dominação é conhecida como colonialismo" (QUIJANO, 1992 p.1).

Desde o século XVI, a colonização europeia em terras americanas introduziu um sofisticado sistema repressivo, que começará nos primeiro anos com a força bélica, e, com o passar do tempo sendo disseminado de outras formas. Destacando o discurso ${ }^{1}$ como a forma mais expressiva até os dias de hoje, onde "A repressão recaiu sobre os modelos de conhecer, de produzir conhecimento, sobre os recursos, padrões e instrumentos de expressão formalizada e objetivada, intelectual ou visual" (QUIJANO, 1992, p.2), onde a "A América latina é, sem dúvida, o caso extremo da colonização cultural da Europa" (QUIJANO, 1992, p.3).

Diante disso, o percurso histórico da formação cultural americana, incluindo a brasileira, consolidou um modelo onde à importação de modelos, costumes e padrões é fator chave para o alcance de um determinado "avanço" e "desenvolvimento", demonstrando mais uma vez que "é no norte que mora a novidade" (PACHECO, 2019, p.38). Cabe ressaltar que em sua maioria, os modelos educacionais importados da Europa é uma extensão de um modelo baseado no instrucionismo, característica essa introduzida à educação após revolução industrial. Esse instrucionismo tem como foco principal não a aprendizagem, e sim, a

\footnotetext{
10 discurso designa, em geral, para Foucault, um conjunto de enunciados que podem pertencer a campos diferentes, mas que obedecem, apesar de tudo, a regras de funcionamento comuns. Essas regras não são somente lingüísticas ou formais, mas reproduzem um certo número de cisões historicamente determinada (por exemplo, a grande separação entre razão/desrazão): a "ordem do discurso" própria a um período particular possui, portanto, uma função normativa e reguladora e coloca em funcionamento mecanismos de organização do real por meio da produção de saberes, de estratégias e de práticas (REVEL, 2005).
} 
instrumentalização de um modelo tecnicista, onde a finalidade da educação e meramente a produção de mão de obra para o mercado capitalista.

\section{A Escola no Campo Neoliberal Contemporâneo}

A escola a parti da primeira revolução industrial, passar a ser outro campo, um campo modernizado, onde terá o papel de treinar os corpos para o trabalho da linha de montagem, e, além disso, docilizar esse corpos aos inúmeros sistemas de Estado. Por muitas vezes pergunta-se "Por que há aula, turma, sério/ano de escolaridade, intervalo, 200 dias letivos" (PACHECO, 2019, p.33), essas similaridades com estrutura fabril, mostra o quão o modelo brasileiro é escravocrata, imperialista e perpetuador das desigualdades enraizadas no mundo. Com isso, é de extrema importância "ajudar os professores a perceber a que senhor a escola está servindo" (PACHECO, 2019, p.39), e os posicionar contra os "inertes produtos do pensamento humano" (PACHECO, 2019, p.40).

Assim, o ato de educar deve alicerçar-se numa ética, onde, a emancipação do ser humano é a prioridade. O educador necessita compreender que "a inteligência (também) passa pelos sentidos" (PACHECO, 2019, p.36) e que vai muito além da instrução técnica e resolução de equações matemáticas. Apesar de que, a formação dos educadores no Brasil segue o modelo técnico e eurocêntrico, onde o ritmo das aulas são baseadas no educador enquanto detentor único e exclusivo do saber, com isso, acarretando em "mais dificuldades de aprendizagem nos professores do que nos alunos" (PACHECO, 2019, p.36) e que, o modelo de fazer ciência segue estritamente o modelo europeu, onde, "Paradigma cartesiano, criou a estrutura de produção de conhecimento baseado em sujeito e objeto" (QUIJANO, 1992, p.4).

No qual o sujeito é o homem, branco, europeu, detentor de todo o saber e racionalização, e o objeto fica a cargo de todos os povos colonizados e explorados por esse europeu, onde, o sujeito é forçado a sobrepor em subjetividade toda a sua cultura, saberes e costumes, em detrimento da conquista da racionalização/modernização eurocêntrica. Entretanto,

Não é necessário, contudo, recusar toda a ideia de totalidade para desprender-se das ideias e imagens como as quais se elaborou essa categoria dentro da modernidade europeia. O que se deve fazer é algo muito diferente: libertar a produção do conhecimento, da reflexão e da comunicação das covas da racionalidade/modernidade europeia (QUIJANO, 1992, p.9). 
Assim, faz-se necessário alterar os modelos impostos de forma coercitiva, modificando, mesmo que lenta e gradual, as estruturas educacionais vigentes. $\mathrm{E} o$ educador é peça fundamental nessa desobediência social, política e epistêmica. Onde, a cada dia torna-se "inevitável à criação de condições de melhoria da qualidade da educação, da sustentabilidade socioambiental, da promoção da gestão democrática e da cidadania" (PACHECO, 2019 p. 43).

Cabe ressaltar que, uma transformação na estrutura de qualquer sistema de educação, seja ela qual for, deverá seguir passos minuciosos, pois, as decisões a serem tomadas durante esse processo alterará modos de vida de inúmeros indivíduos, que muitas vezes não participam de forma ativa nesse processo. E para que as melhores decisões sejam tomadas, deve-se trabalhar em coletivo, com bastantes discussões às proposições de todos os seguimentos, pois, "No campo da educação um projeto inovador é sempre um ato coletivo" (PACHECO, 2019, p.45), importante também saber que "A prática docente, especificamente humana, é profundamente formadora; por isso ética" (PACHECO, 2019, p.47).

Esse caminho ético a ser seguido pelos que pensam e fazem educação, deverá nortear-se pela premissa do verdadeiro acesso à educação, pois, muitas das vezes os que pensam educação, principalmente os pensadores do norte, não analisam e não incorporam fatos socioculturais e socioeconômicos nas políticas e modelos de educação elaborados por si, assim, gerando a "Sofisticação do discurso e a miséria das práticas" (PACHECO, 2019, p.48).

\section{A Escola e suas Possibilidades na Emancipação Humana}

Ao se pensar educação, é impreterivelmente necessário pensar sociedade e indivíduo, haja vista, que em todos os países do mundo, em especial o Brasil há uma pluralidade desses dois seguimentos. Assim, o ato de inovar no âmbito educacional "equivale a operar rupturas paradigmáticas" (PACHECO, 2019, p.49), não podendo essa inovação ser importada, geral e coercitiva, sem que o seu criador não conheça de forma ampla a realidade do espaço que fará uso desses "processos inovatórios". A saber, o que seria inovação na educação:

Significa trazer à realidade educativa algo efetivamente novo, ao invés de não modificar o que seja considerado essencial. Pressupõe não a mera adoção de novidades, inclusive as tecnologias, mas mudança na forma de entender o conhecimento (PACHECO, 2019, p.53). 
Faz-se necessário esse entendimento do que seria a inovação na educação, pois, muitas das vezes grandes empresas, administradas por grandes fundações financeiras "criam" e exportam "inovações" educacionais, que na prática só são modelos já existentes e usados em todo o mundo com algumas alterações e/ou implantação de tecnologias digitais de comunicação e informação e tornam-se produtos de grandes propagandas, servindo ao senhor Neoliberalismo e aos interesses do mercado. E é importante frisar que

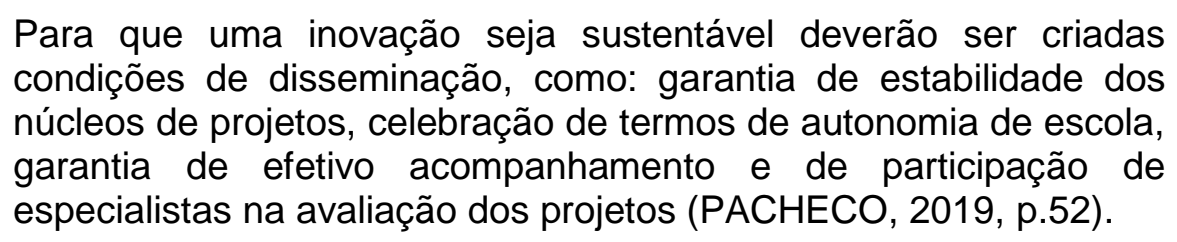

Com isso, ao se pensar educação nos dias de hoje, precisa-se primeiramente pensar para que sociedade é essa educação, quais os interesses sociais estão enraizados nesse sistema de educação e para qual fim é essa educação. Desviando dos caminhos neoliberais, da usurpação das soberanias nacionais e lembrando que "O otimismo é da natureza do tempo e a esperança é da natureza da eternidade" (PACHECO, 2019 p.52) e que a educação deve gerar "Vida gratuita" a todas e todos os cidadãos.

Mas para que essa educação torne-se um direito de todos e todas, assentados na ideia de emancipação humana, é preciso, urgentemente "a descolonização epistemológica para dar espaço a uma nova comunicação intelectual, uma troca de experiências e de significações, como a base de outra racionalidade que possa pretender, com legitimidade, alguma universalidade" (QUIJANO, 1992, p.9).

A todas e todos aqueles que pensam, fazem e exercer a educação, pensar uma educação multi-interdiciplinar, alicerçada na diversidade e pluralidade das ideias, muitas vezes, é quebrar barreiras, ver em outros horizontes, ou até mesmo abdicar de convicções pessoais em detrimento do coletivo. E nesse longo e árduo caminho, muitas das vezes a tecnologia adentra o rol de discussões, onde, tecnicamente seria para auxiliar o amadurecimento e aperfeiçoamento da educação e da ciência, as torna mais enrijecidas, frias e sem "sentimento" de humanidade. Pois, "Com a tecnologia, inventamos modos de manipulação novos e muito sutis, pelos quais a manipulação exercida sobre as coisas implica na subjugação dos homens pelas técnicas de manipulação" (MORIN, 2005, p.108). Assim, a quebra de paradigmas é necessária que aconteça de forma diária e contínua, que os que façam educação, 
criem e perpetuem uma identidade política, inclusive na política institucional, onde boa parte das decisões são tomadas, com isso, quebrando as pensamentos imperialistas e colonizadores (MIGNOLO, 2008).

Entretanto, hora alguma podemos ver a tecnologia, em especial, as de informação e comunicação como rivais à inovação educacional e científica, é preciso "discutir a validade e torná-la como algo absoluto, de compreender que não existe neutralidade nas inovações tecnológicas, que elas podem ser utilizadas para o bem e para o mal, a favor ou contra o homem" (BAZZO; COLOMBO, 2001, p.3).

\section{Considerações Finais}

Por certo, a literatura até por hora produzida, faz um lindo exercício de pensamento e nos dar alguns caminhos e opções, dentre elas a descolonialidade. Entretanto, "Os processos de criatividade e de invenção não são redutíveis à lógica da máquina artificial" (MORIN, 2005, p.110), porém, o que se observa ao longo da década de 90 e a primeira década do século XXI, é uma supervalorização da técnica pela técnica, do instrumento pelo instrumento, e deixando de lado suas inúmeras análises sociofilosóficas que não inerentes à condição humana.

Isso mostra o quão o olhar desenhado e pensado pelo artista M. C. Escher reproduz essa lógica mundial, de produzir por produzir e gerar "desejos" e "vontades" ao homem. Porém, sem se deslocar das ideias predadoras do capital, com o viés imperialista e escravocrata. A vida na era da informação reduziu-se cada vez mais em algoritmos, lógica fuzzy, inteligência artificial e "likes" nas redes sociais, e falando nelas, como tornaram instrumentos de decisão do capital, do imperialismo do pensamento e do saber, "guiando" uma massa de bilhões de pessoas à suas escolhas pessoais, desde ao consumo de produtos e/ou até mesmo a escolha de um chefe de Estado. Consolidando cada vez mais a liquidez da vida, do mundo e das coisas (BAUMAN).

Assim, o educador, o pesquisador ou quaisquer outros profissionais da área da educação e que pensam educação, têm um papel crucial nesse longo processo de (des) construção desses sistemas de produção de "verdades", no qual visam gerar a "condição de formação e desenvolvimento do capitalismo" (FOUCAULT, 2018, p. 54). Não se trata somente de um exercício epistemológico do Saber produzido para educação, mas sim, "constituir uma nova política da verdade" (FOUCAULT, 2018, p. 
54), assim, "desvincular o poder da verdade das formas de hegemonia (sociais, econômicas, culturais) no interior das quais ela funciona no momento" (FOUCAULT, 2018, p. 54).

\section{Referências}

BAZZO, W. A.; COLOMBO, C. R. Educação tecnológica contextualizada: ferramenta essencial para o desenvolvimento social brasileiro. Revista de Ensino de Engenharia, Florianópolis, v. 20, n. 1, p. 9-16, 2001.

FOUCAULT, Michel. Microfísica do Poder. Organização, introdução e revisão técnica de Roberto Machado. $7^{\circ}$ ed, Rio de Janeiro/São Paulo. Editora Paz e Terra, 2018.

MIGNOLO, Walter D. Desobediência Epistêmica: a opção descolonial e o significado de identidade em política. Cadernos de Letras da UFF - Dossiê: Literatura, língua e identidade, nº 34, p. 287-324, 2008.

MORIN, Edgar. Ciência com consciência. Tradução de Maria D. Alexandre e Maria Alice Sampaio Dória. Ed. revista e modificada pelo autor. 8 edição, Rio de Janeiro. Bertrand, Brasil, 2005.

SALOMAO, P. E. A. et al. As Tecnologias de Informação e Comunicação (TIC) no ensino superior. Revista Multidisciplinar do Nordeste Mineiro, v. 1, 2018.

PACHECO, José. Inovar é assumir um compromisso ético com a educação. 1ํㅜ Ed, São Paulo. Editora Vozes, 2019.

QUIJANO, Aníbal. Colonialidade e Modernidade/Racionalidade. In: BONILLO, Heradio (comp) Los conquistados. Bogotá: Tercer Mundo Editiones; FLACSO, 1992, pp 437- 449. Tradução de Wanderson Flor do Nascimento.

REVEL, Judith. Michel Foucault: conceitos essenciais / Judith Revel ; tradução Maria do Rosário Gregolin, Nilton Milanez, Carlo Piovesani. - São Carlos : Claraluz, 2005. 